\title{
Methylene blue and its importance in medicine
}

\author{
Yaren Kayabaş1 ${ }^{1}$ (D), Oytun Erbaş ${ }^{1,2}$ (D) \\ ${ }^{1}$ Institute of Experimental Medicine, Gebze-Kocaeli, Turkey \\ ${ }^{2}$ Department of Physiology, Medical Faculty of Demiroğlu Bilim University, Istanbul, Turkey
}

\begin{abstract}
Methylene blue (MB), a blue-colored aniline-based dye that was first developed for the dyeing of cotton, is a phenothiazine derivative that is soluble in water and organic solvents. Its reduced form, leucomethylene blue, is colorless and has a regulatory effect on the redox cycle. This feature allows it to be used in malarial therapy by inducing glutathione reductase (GR), an enzyme of glutathione metabolism. Malaria is a disease characterized by repeated growth cycles of Plasmodium group parasites in erythrocytes and changes in glutathione metabolism. Methylene blue was recognized as an antimalarial agent when it was observed that it reduced reactive oxygen species (ROS) by inhibiting Plasmodium falciparum glutathione reductase and by selectively inducing oxidative stress. It has also been observed that MB can reduce factors that cause aging and Alzheimer's disease, such as the accumulation of tau proteins in plaques, mitochondrial dysfunction, and ROS increase due to disorders in the electron transport chain (ETC). Methylene blue has been used in Alzheimer's treatment, considering its features of tau protein inhibition, anti-ROS antioxidant properties, and ability to regulate ETC. Methylene blue, known for its antimalarial and antioxidant effects, has also been used in the treatment of Candida infections as an antifungal agent. In candidiasis infections, MB is aimed to cause mitochondrial dysfunction in yeast and treat the patient. In this review, the history of MB as an antimalarial, antioxidant and antifungal agent; malaria, Alzheimer's, and its role in the treatment of candidiasis. In this review, the history of MB and its role as an antimalarial, antioxidant, and antifungal agent in the treatment of malaria, Alzheimer's, and candidiasis are discussed.
\end{abstract}

Keywords: Alzheimer's disease, antifungal, antimalarial therapy, candidiasis, electron transport chain, glutathione reductase, methylene blue, mitochondrial dysfunction, tau proteins.

Methylene blue (MB, methylthioninium chloride), a phenothiazine known for its ability to cross the blood-brain barrier and exert neuroprotective effects, is considered a potential therapy, especially for neurodegenerative diseases. ${ }^{[1,2]}$ Among its beneficial properties, $\mathrm{MB}$ is a redox cycle stabilizer and an electron donor. ${ }^{[1]}$ Studies have found that $\mathrm{MB}$ can be both a substrate and an inhibitor of glutathione reductase, which is an important enzyme of glutathione metabolism, ${ }^{[3]}$ and its ability to target Plasmodium falciparum glutathione reductase (PfGR) instead of human glutathione reductase (hGR) at therapeutic concentrations has attracted considerable attention in antimalarial therapy. ${ }^{[4]}$ In addition, MB is also used in the treatment of
Alzheimer's disease (AD), ${ }^{[5]}$ which occurs as a result of mitochondrial dysfunction, neuroinflammation, and oxidative stress. It is also known that defects in mitochondrial functions, which are responsible for energy production in the cell, occur before the accumulation of amyloid $\beta(\mathrm{A} \beta)$ that causes $\mathrm{AD}$ and are closely related to the accumulation of tau protein. ${ }^{[6,7]}$ Studies have shown that MB can delay aging by inhibiting the accumulation of tau protein ${ }^{[8]}$ and by increasing mitochondrial respiration, ${ }^{[9]}$ hence it is considered a significant chemical in regards to $\mathrm{AD}$. Candidiasis, an infection caused by Candida spp., ${ }^{[10]}$ is the result of carbohydrate-active enzymes acting on the cell wall which lead to wall remodeling, changes in stress resistance, and extracellular matrix

Received: October 10, 2020 Accepted: November 05, 2020 Published online: December 16, 2020

Correspondence: Yaren Kayabaşı. Deneysel Tıp Enstitüsü, 41470 Gebze-Kocaeli, Türkiye. Tel: +90 533 - 5163387 e-mail: kayabasi.yrn@hotmail.com 
accumulation..$^{11]}$ They usually cause infection by forming biofilms on implanted medical devices. ${ }^{[12]}$ Many studies have attempted to prevent multiple drug resistance that develops after interventions used to eliminate candidiasis (surgery and antifungal agents). ${ }^{[13]}$ While $\mathrm{MB}$ is known for causing mitochondrial dysfunction and changes in redox cycling ${ }^{[5]}$ its use in candidiasis treatment as well as its antifungal and antioxidant properties have also been recognized. ${ }^{[14]}$ In addition to these diseases, $\mathrm{MB}$ is also involved in the treatment of methemoglobinemia, encephalopathies, and neurodegenerative disorders. ${ }^{[15]}$ This review discusses the role of $\mathrm{MB}$ only in the treatment of malaria, $\mathrm{AD}$, and candidiasis.

\section{METHYLENE BLUE}

Methylene blue was first synthesized in 1876 by the German chemist Heinreich Caro (1834-1911) as an aniline-based dye for cotton dyeing. ${ }^{[16]}$ Methylene blue (chemical name: tetramethylthionine chloride) is a cationic dye and belongs to the class of compounds known as phenothiazines (neuroleptic drug group). ${ }^{[17]}$ It is soluble in water and organic solvents. ${ }^{[18]}$ It is in the oxidized state and dark blue in color, showing maximum absorption at 609-668 nm wavelengths. Since it cannot be absorbed in the visible region, it is reduced to leucomethylene blue (leucoMB) and becomes colorless. ${ }^{[19]}$ These two forms of dye exist in equilibrium as a redox pair; together they form a reversible oxidationreduction system or electron donor-acceptor pair. ${ }^{[9]}$

In 1885, Paul Ehrlich published an article on the staining of the tuberculosis bacillus, called the "side-chain theory", which described the theory of affinity of tissues for various chemical compounds. ${ }^{[23]}$ According to the sidechain theory, the interaction between synthetics is chemical by nature of compounds and tissues and involves a chemical reaction. In other words, the biological effect of any substance depends on the chemical structure of the substance and the cell. Ehrlich studied the staining intensity of various organs by injecting $\mathrm{MB}$ into live animal tissue. ${ }^{[23]}$ He conducted similar experiments in different animal species, using other synthetic dyes. As a result of these experiments, he proposed that $\mathrm{MB}$ has a selective affinity for nerve tissue due to its stabilizing properties on redox cycling. ${ }^{[8]}$ Considering the side-chain theory, Ehrlich suggested that if pathogens could be stained with $\mathrm{MB}$, such staining could have a certain detrimental effect on the pathogen. ${ }^{[24]}$ Methylene blue began to be used as a drug to treat various diseases to eliminate only pathogens, without harming other tissues. ${ }^{[25]}$ Furthermore, MB also plays an important role in many diseases such as neurodegenerative and psychiatric disorders (Figure 1) and Candida albicans infections. ${ }^{[26]}$

\section{METHYLENE BLUE IN ANTIMALARIAL TREATMENT}

Malaria is a disease characterized by repeated growth cycles of Plasmodium group parasites (P. falciparum, P. vivax, P. malariae, P. knowlesi, $P$. ovale) in erythrocytes. Various cellular and molecular strategies allow the parasite to escape

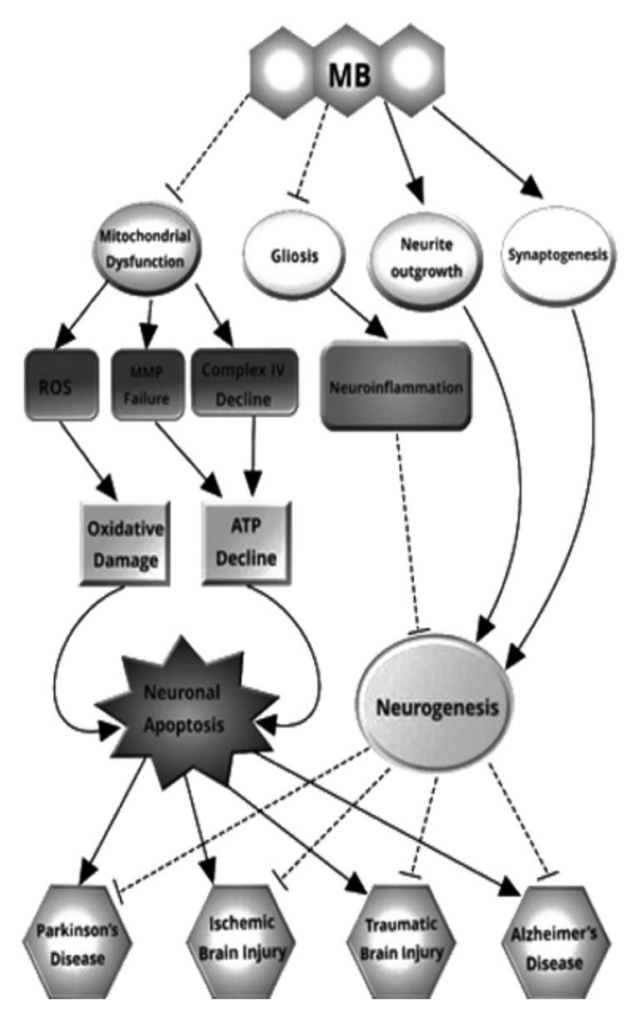

Figure 1. The role of MB in neurodegeneration. Methylene blue can protect against neuronal apoptosis by preventing mitochondrial dysfunction and subsequent oxidative damage and ATP loss. Methylene blue supports neurogenesis by improving neuroinflammation and promoting neurite outgrowth and synaptogenesis. In this manner, MB can prevent neuronal damage and facilitate neuronal repair. ${ }^{[26]}$ 
from the human immune response so they can go through multiple reproductive cycles. ${ }^{[27]}$ During the erythrocyte cycle, soluble products of Plasmodium spp, known as malarial toxins, guide the systemic release of proinflammatory cytokines (molecules that control immunological events such as activation, proliferation of immunocompetent cells, and regulation of cells in tissues) that act on many other cellular systems such as the endothelium. ${ }^{\text {[28] }}$

After Plasmodium falciparum glutathione reductase (PfGR) emerged as a new drug target, ${ }^{[29]}$ interest in $\mathrm{MB}$ as an antimalarial drug increased when $\mathrm{MB}$ was also found to be an inhibitor and substrate of glutathione reductase. ${ }^{[3]}$ Glutathione is an antioxidant that can prevent damage to cellular components by reactive oxygen species (ROS) such as free radicals, peroxides, lipid peroxides, and heavy metals; ${ }^{[30]}$ it exists in reduced (GSH) and oxidized (GSSG) states. The ratio of reduced glutathione to oxidized glutathione (GSH/GSSG) in cells is a measure of cellular oxidative stress. ${ }^{[31,32]}$ Glutathione reductase (GR) enzyme plays a role in regulating intracellular redox balance (Figure 2), ${ }^{[20-22]}$ preserving macromolecules such as proteins, and controlling glutathione-dependent antioxidant systems; ${ }^{[33]}$ intracellular $\mathrm{SH} / \mathrm{SS}$ ratio ${ }^{[34]}$ is maintained by increasing GSH/GSSG ratio. ${ }^{[22]}$ Like redox cyclers, $\mathrm{MB}$ uses glutathione reductase to regenerate $e^{[35-37]}$ and was found to target PfGR rather than human glutathione reductase (hGR) at therapeutic concentrations. ${ }^{[4]}$ Studies have shown that the development of resistance to $\mathrm{MB}$ is difficult in vivo activity, ${ }^{[38]}$ and that $\mathrm{P}$. falciparum and $P$. vivax have strong in vivo activity against drugresistant isolates. ${ }^{[39,40]}$ It was also found that MB has a substantial effect on gametocyte reduction in P. falciparum. ${ }^{[41]}$ For this reason, methylene blue was found to be a potentially useful partner drug for artemisinin-based combination therapy (ACT; a treatment method in which potent drugs are used in combination with artemisinin), especially when elimination is the ultimate goal. ${ }^{[42]}$

\section{MITOCHONDRIAL DYSFUNCTION AND METHYLENE BLUE IN ALZHEIMER'S TREATMENT}

The brain is dependent on oxidative metabolism as an energy source, consuming $20 \%$ of the body's glucose and $20 \%$ of oxygen at resting state. ${ }^{[43]} \mathrm{A}$ large portion of this energy requirement consists of maintaining resting membrane potential, forming action potentials, and postsynaptic effects of glutamate. ${ }^{[44,45]}$ Considering the damage to the brain as a result of deficiency of these energy sources, proper mitochondrial function is considered crucial to the brain. In contrast, dysfunctional mitochondria cause neurodegenerative conditions. ${ }^{[46]}$ Mitochondria are major organelles in neurons. ${ }^{[47]}$ and generate energy as adenosine triphosphate (ATP) via oxidative phosphorylation or the mitochondrial respiratory chain. ${ }^{[48,49]}$ Other functions of mitochondria include regulation of calcium homeostasis, formation of free radicals, and apoptosis. ${ }^{[50]}$ Mitochondrial dysfunction results in problems such as changes in mitochondrial respiratory chain enzymes, formation of reactive oxygen species (ROS), opening of the mitochondrial permeability transition pore (mPTP), structural abnormalities of the mitochondria, oxidative stress, and<smiles>CN(C)c1ccc2c(c1)Sc1cc(N(C)C)ccc1N2</smiles>

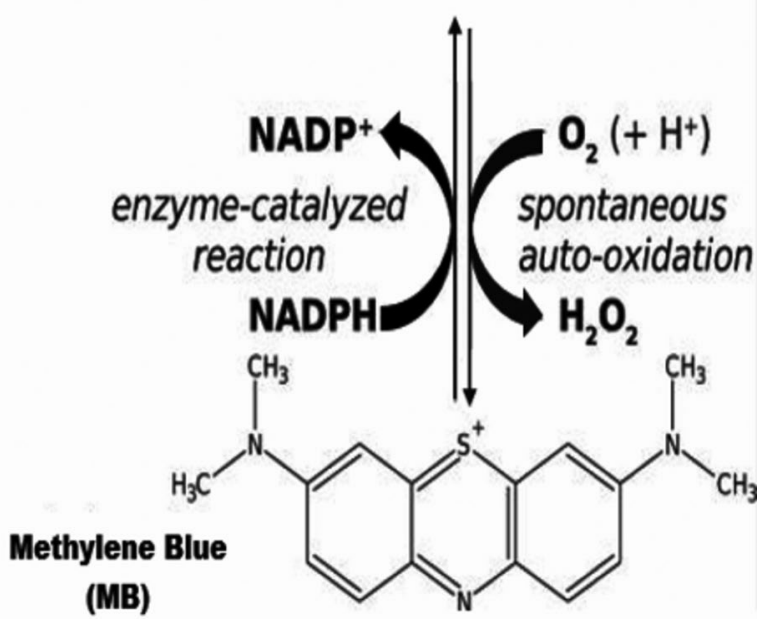

Figure 2. Methylene blue uses glutathione reductase (an enzyme of glutathione metabolism that maintains the -SH group in proteins by reducing oxidized glutathione [GSH] in the cell ${ }^{[20,21]}$ ) as a substrate and transforms to leucomethylene blue; leucomethylene blue is an autooxidizer and spends $\mathrm{O}_{2}$ in each cycle to reduce $\mathrm{O}_{2}{ }^{[22]}$ 
apoptosis. ${ }^{[51-53]}$ Proper mitochondrial function depends on the successive passage of electrons at each step of the electron transport chain (ETC). ${ }^{[54]}$ The primary function of mitochondrial ETC is the step by step transfer of high-energy electrons from food-derived energy substrates such as $\mathrm{NADH}$ to $\mathrm{O}_{2}$. At each step, the energy used to carry protons is released and ATPsynthase synthesizes ATP from ADP by creating a proton gradient between membranes. ${ }^{[5,55]}$ When the ETC is fully occupied, electron carriers begin to transport electrons to $\mathrm{O}_{2}$ producing harmful reactive oxygen species (ROS). ${ }^{[54}$ The greatest risk for neurodegenerative diseases such as $\mathrm{AD}$ is aging, and the accumulation of mitochondrial DNA (mtDNA) mutations and ROS production, which are also observed in Alzheimer's pathogenesis, have been observed to cause aging. ${ }^{[52]}$

Alzheimer's disease is a progressive neurodegenerative disease characterized by decreased cognitive functions, self-care deficiencies, and various neuropsychiatric and behavioral disorders due to neuron and synapse losses in various parts of the central nervous system (CNS). ${ }^{[56,57]}$ Approximately 5-10\% of cases are genetic and emerge in an early onset, autosomal dominant manner. Three proteins are known to be associated with such genetic events: amyloid precursor protein (APP), and presenilin 1 and 2 (PS 1 and PS 2). ${ }^{[52]}$ Alzheimer's disease involves extracellular accumulation of $A \beta$ derived from APP, in senile plaques composed of hyperphosphorylated tau protein. ${ }^{[58,59]}$ Amyloid precursor protein is metabolized to $A \beta$ in two ways. The first of these, the non-amyloidogenic pathway, is the metabolic pathway involving $\beta$-secretase and $\beta$-secretase enzymes that break down APP, and the products formed are not toxic. In the second pathway, the amyloidogenic pathway involves the formation of $A \beta 1-40$ and $A \beta 1-42$ derived from $\beta$-secretase and $\beta$-secretase enzymes. ${ }^{[60,61]} A \beta 1-40$ constitutes approximately $90 \%$ of $A \beta$. However, the main component of amyloid accumulation is $A \beta 1-42 .{ }^{[62]}$ Therefore, neurotoxic $A \beta$ derivatives that form in the amyloidogenic pathway accumulate in amyloid plaques, causing damage to synapses and hyperphosphorilation in tau proteins. It has been observed that mutations in the PS 1 gene cause toxic $A \beta$ production and hyperphosphorylation of tau proteins as a result of improper cleavage of APP, triggering the formation of neural fibrillar tangles (NFT). ${ }^{[63]}$

The therapeutic research of $\mathrm{AD}$ first targeted $A \beta$, and $M B$ has been studied since $2007 .{ }^{[64]}$ In a study on transgenic mice (3xTg-AD), it was observed that $\mathrm{MB}$ mediated the proteolytic clearance of $A \beta$ by increasing chymotrypsin and trypsin-like proteasome (large protein structure) activity in the brain. ${ }^{[65]}$ In another transgenic mouse (APP/PS1) model, reduced $A \beta$ accumulation in the hippocampus and adjacent cortex was observed, providing protection against cognitive decline in behavioral tasks that measure social interaction, learning and memory, as well as exploratory activity. ${ }^{[66]}$ These results obtained from APP/PS1 mice has been attributed to the anti-amyloidogenic mechanism and reduced $\beta$-secretase activity and expression. ${ }^{[67]}$

Mitochondrial dysfunction in Alzheimer's is determined by a decrease in complex IV, a decrease in other TCA cycle (citric acid cycle) enzymes, and mutations in mtDNA. Degradation in mitochondrial complex IV increases the production of free radicals and oxidants such as hydrogen peroxide $\left(\mathrm{H}_{2} \mathrm{O}_{2}\right)$. Lack of energy is a severe consequence of impaired mitochondrial function. Aging also plays a role in neural dysfunction. ${ }^{[68]}$ It is suggested that research to find therapeutic strategies to increase mitochondrial function may delay aging. ${ }^{[69]}$

Methylene blue is the first chemical that can cross the blood-brain barrier ${ }^{[70]}$ and induce the mitochondrial respiratory complex. ${ }^{[68]}$ Methylene blue, applied in low doses, exhibits strong antioxidant properties, and its oxidized and reduced forms are balanced in low concentrations (Figure 2). Thus, it protects against oxidative damage and ensures the continuation of mitochondrial function. ${ }^{[71]}$ Methylene blue prevents aging and neurodegeneration by affecting mitochondria and cytochrome c, through its cycling between its oxidized and reduced forms. ${ }^{[24]}$ By penetrating the cellular and mitochondrial membranes, MB aggregates in the mitochondria and increases mitochondrial respiration by transferring electrons to oxygen in the ETC. Cytochrome c oxidase is the last member of the electron transport chain, and decreased activity of this enzyme has been reported in $\mathrm{AD}$. Methylene blue induces 
cytochrome c oxidase and increases its enzymatic activity, therefore increasing oxidative metabolic capacity of neurons and allowing ATP production in the brain by consuming more oxygen. Methylene blue also increases the production of cytochrome c oxidase. ${ }^{[9]}$ The potential use of $\mathrm{MB}$ in the treatment of $\mathrm{AD}$ has also been suggested because of its features of tau filament formation and its inhibitory properties on $A \beta$ aggregation (Figure 3). ${ }^{172]}$ Amyloid $\beta$ aggregation occurs by a mechanism consisting of multiple pathways, comprising of $\mathrm{A} \beta$ aggregate derivatives such as oligomers, protofibrils, and circular protofibrils. It has been observed that the addition of $\mathrm{MB}$ to previously formed oligomers causes oligomer loss and oligomer formation is inhibited due to increased fibril formation. ${ }^{[64]}$

These mechanisms of effect indicate that MB displays its therapeutic effect on neurodegenerative diseases through various pathways.

\section{CANDIDA ALBICANS AND THE USE OF METHYLENE BLUE}

Candidiasis is a common fungal infection that occurs in the skin, oral cavity and esophagus, gastrointestinal system, vaginal, and vascular system in humans caused by caused by the Candida genus of yeast. ${ }^{[73]}$ Candida species are the cause of the fourth most common hospitalacquired bloodstream infections received in the USA and systemic candidiasis has a high mortality rate of up to $50 \% \cdot{ }^{[74]}$ Although only

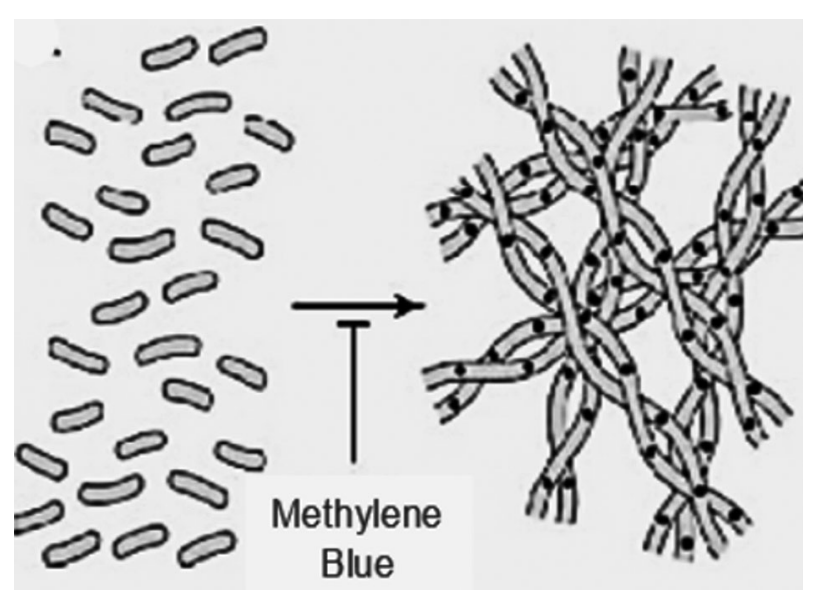

Figure 3. Inhibition of tau aggregation. Methylene blue prevents the formation of tau aggregates called paired helical filaments. ${ }^{[8]}$ five species cause the vast majority of Candida infections (Candida albicans, Candida glabrata, Candida parapsilosis, Candida tropicalis, and Candida krusei), ${ }^{[75-79]}$ Candida albicans is most responsible for infections. ${ }^{[73]}$ Differences in Candida spp. colonization and survival strategies have been associated with certain risk groups, indicating that they only promote infections under different preconditions. For instance, infections associated with $\mathrm{C}$. glabrata and $\mathrm{C}$. tropicalis are more common in patients with hematological or solid organ malignancies and neutropenia. Candida krusei infections occur especially in patients who have underwent hematopoietic stem cell transplantation. Candida parapsilosis is associated with infections in newborns rather than adults and is a common pathogen of catheter-related infections. ${ }^{[80]}$ Candida albicans is a commensal organism that is usually found in the human body but causes superficial and systemic infections in immunocompromised conditions. ${ }^{[81]}$ It also draws attention as a highly versatile organism, with the ability to survive in a wide variety of settings, each with their own unique environmental conditions. This ability grants Candida albicans and Candida spp. an advantage over other microorganisms. With limited nutrients on mucosal surfaces, competition between bacteria and fungi (microbiota) provide selective conditions causing less adapted microorganisms to be eliminated. Most bacterial microbiota are known to regulate their catabolic and anabolic pathways in states of limited or excessive nutrition, but have not been characterized despite the knowledge of parallel systems existing among human pathogenic fungi. ${ }^{[82]}$ For instance, most Candida-specific genes (compared to Saccharomyces cerevisiae) encode catabolic proteins and some of these genes may explain the organism's commensal and pathogenic survival. ${ }^{[83]}$ Other well-known features include genomic diversity resulting from interchangeable cell morphologies, the ability to change the colony phenotype at high frequencies, and a predisposition to "chromosomal shuffling" mechanisms. ${ }^{[84]}$

Candida albicans, which lives in harmony with other members of microbiota in people with healthy immune systems, rapidly reproduce and cause infection as a result of balance disorders caused by changes in the local environment 
( $\mathrm{pH}$ changes or dietary changes), antibiotic use, or changes in the immune system (due to infection or immunosuppressive therapy); ${ }^{[85-87]}$ these changes induce hyphae formation in response to unfavorable growing conditions or environmental signals that presumably indicate a hostile environment. ${ }^{[88,89]}$ Many virulence-related traits of pathogenic Candida species have evolved to facilitate commensal survival, for example in the fluctuating environment of the gut and to compete with commensal bacteria. Acquired mechanisms to cope with adverse conditions as a commensal organism may also promote virulence, as they equip the fungus with the weapons necessary to overcome host barriers. ${ }^{[00,91]}$

Candida albicans forms highly structured biofilms composed of multiple cell types (round budding yeast cells, oval pseudohyphae cells, and long hyphal cells) located in an extracellular matrix. ${ }^{.93]}$ Candida albicans is often isolated from infections related to medical devices, including urinary and central venous catheters, pacemakers, mechanical heart valves, joint prostheses, contact lenses, and dentures (Figure 4). ${ }^{[92,94]}$ When a Candida albicans biofilm forms on an implanted medical device, it acts as a reservoir for pathogenic cells, is highly resistant to drugs and the host immune system, and has the potential to cause generalized bloodstream infections (candidiasis). ${ }^{12]}$ Since these fungal biofilms are largely resistant to known antifungal drugs ${ }^{[95]}$ treatment of these infections involves the surgical removal of the colonized medical device in combination with administration of high doses of antifungal agents. ${ }^{[96]}$ However, the excessive use of these antifungal drugs causes significant complications, severe side effects, higher costs, lower efficiency, as well as the development of multi-drug resistance. ${ }^{[13]}$

Methylene blue, which is used in the treatment of many diseases due to its high photostability and easy elimination from the body, ${ }^{[97]}$ has also been used as an antifungal by applying photodynamic therapy in Candida albicans vaginal candidiasis in murine models. ${ }^{[98,99]}$ One study demonstrated that the antifungal effect of $\mathrm{MB}$ is due to

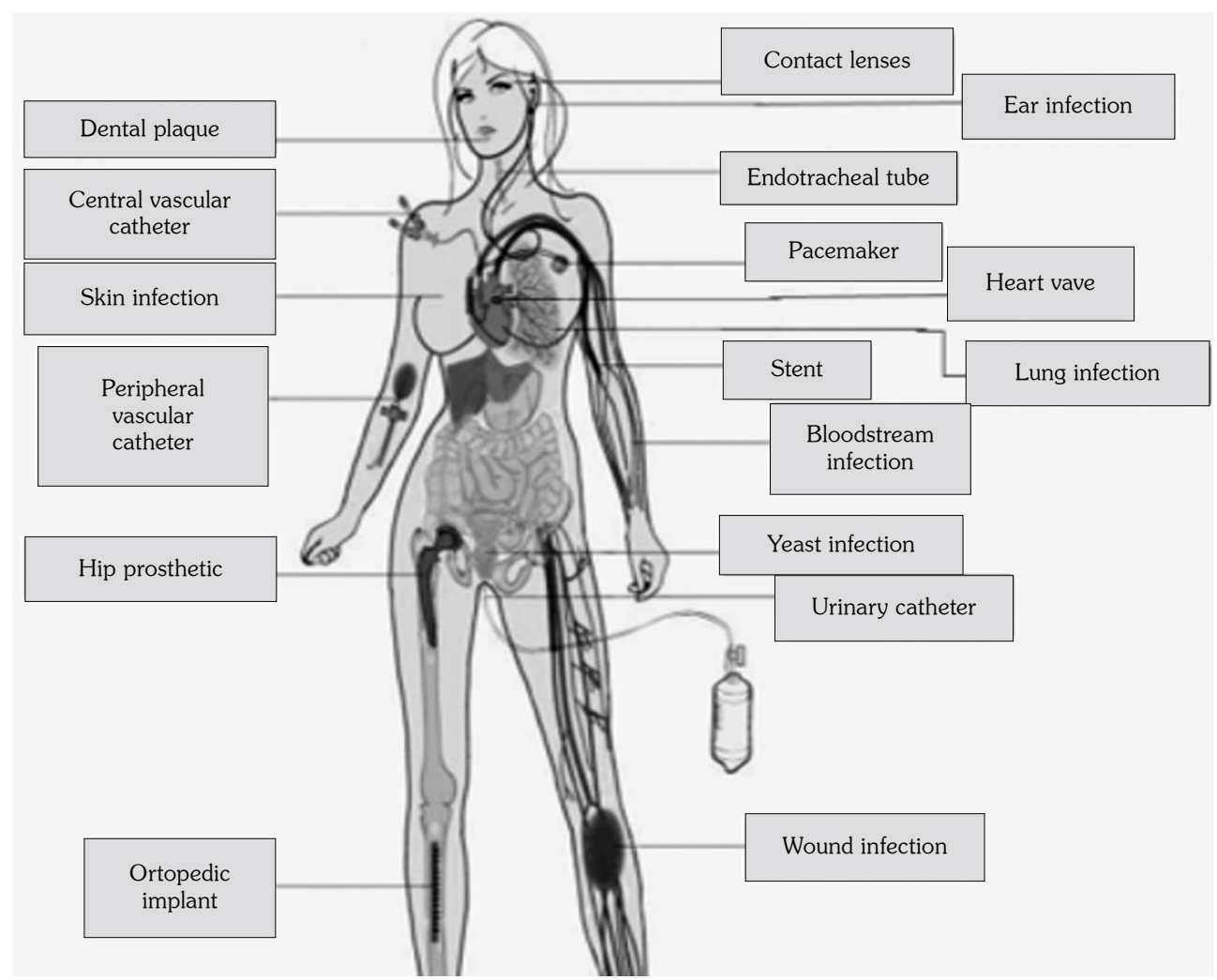

Figure 4. Generalized infections related to Candida albicans. ${ }^{[92]}$ 
mitochondrial dysfunction and changes in the redox cycle, as well as membrane homeostasis, which is the target of many antifungals. Yeast-tohyphae switching is one of the most important factors dictating virulence in Candida albicans infections. One study observed that filamentation was completely absent in MB-treated cells and were present only in yeast form, unlike Candida cells that were not treated with MB. ${ }^{[14]}$ We can argue that $\mathrm{MB}$, which is mostly known for its antioxidant properties, can also be used as an antifungal agent to prevent MDR development, based on its ability to cause mitochondrial dysfunction in Candida, affecting the redox cycle, and preventing hyphae formation.

\section{DISCUSSION AND CONCLUSION}

Methylene blue, an aniline-based thiazine dye that was used for cotton dyeing in the 1800 s, has been used in the treatment of many diseases in later years. First proposed by Paul Ehrlich that it could neutralize pathogens, MB was used in the treatment of the malaria epidemic that occurred during World War I and yielded positive results. Later, MB began to be used in multi-drug therapies to amplify its effect. With the discovery of its antioxidant properties, it was proposed as a therapeutic agent in neurodegenerative and psychotic disorders with its features of mitochondrial dysfunction and redox cycle regulation. Methylene blue has been proven to inhibit the accumulation of tau proteins, which is considered among the causes of $\mathrm{AD}$, treat mitochondrial dysfunction with its regulating effect on the redox cycle, and to inhibit formation of ROS molecules. Thus, it has become a very specific agent in the treatment of neurodegenerative disorders, especially AD. Although the Candida genus of yeast are commensal organisms, their formation of biofilms on medical devices implanted in the body causes candidiasis infections. With the knowledge of the antioxidant properties of $\mathrm{MB}$, it has been observed to reduce infection by causing mitochondrial dysfunction in yeast. The antifungal property of MB has been demonstrated in candidiasis treatment. Considering that $\mathrm{MB}$ is also used in other conditions such as methemoglobinemia, psychiatric disorders, and vasoplegic syndrome, it is evident that $\mathrm{MB}$ is a highly multifunctional agent.

\section{Declaration of conflicting interests}

The authors declared no conflicts of interest with respect to the authorship and/or publication of this article.

\section{Funding}

The authors received no financial support for the research and/or authorship of this article.

\section{REFERENCES}

1. Rojas JC, Bruchey AK, Gonzalez-Lima F. Neurometabolic mechanisms for memory enhancement and neuroprotection of methylene blue. Prog Neurobiol 2012;96:32-45.

2. Walter-Sack I, Rengelshausen J, Oberwittler $\mathrm{H}$, Burhenne J, Mueller $\mathrm{O}$, Meissner $\mathrm{P}$, et al. High absolute bioavailability of methylene blue given as an aqueous oral formulation. Eur J Clin Pharmacol 2009;65:179-89.

3. Biot C, Bauer H, Schirmer RH, Davioud-Charvet E. 5-substituted tetrazoles as bioisosteres of carboxylic acids. Bioisosterism and mechanistic studies on glutathione reductase inhibitors as antimalarials. $\mathrm{J}$ Med Chem 2004;47:5972-83.

4. Färber PM, Arscott LD, Williams CH Jr, Becker $\mathrm{K}$, Schirmer RH. Recombinant Plasmodium falciparum glutathione reductase is inhibited by the antimalarial dye methylene blue. FEBS Lett 1998;422:311-4.

5. Kumar A, Singh A. A review on mitochondrial restorative mechanism of antioxidants in Alzheimer's disease and other neurological conditions. Front Pharmacol 2015;6:206.

6. Giannoni P, Fossati S, Marcello E, Claeysen S. Editorial: Identification of multiple targets in the fight against Alzheimer's disease. Front Aging Neurosci 2020;12:169.

7. Maruszak A, Zekanowski C. Mitochondrial dysfunction and Alzheimer's disease. Prog Neuropsychopharmacol Biol Psychiatry 2011;35:320-30.

8. Ohlow MJ, Moosmann B. Phenothiazine: the seven lives of pharmacology's first lead structure. Drug Discov Today 2011;16:119-31.

9. $\mathrm{Oz} \mathrm{M}$, Lorke DE, Petroianu GA. Methylene blue and Alzheimer's disease. Biochem Pharmacol 2009;78:927-32.

10. Bambach A, Fernandes MP, Ghosh A, Kruppa M, Alex D, Li D, et al. Goa1p of Candida albicans localizes to the mitochondria during stress and is required for mitochondrial function and virulence. Eukaryot Cell 2009;8:1706-20.

11. Sorgo AG, Heilmann CJ, Brul S, de Koster CG, Klis FM. Beyond the wall: Candida albicans secret(e)s to survive. FEMS Microbiol Lett 2013;338:10-7.

12. Gulati M, Nobile CJ. Candida albicans biofilms: development, regulation, and molecular mechanisms. Microbes Infect 2016;18:310-21. 
13. Farmakiotis D, Tarrand JJ, Kontoyiannis DP. Drugresistant Candida glabrata infection in cancer patients. Emerg Infect Dis 2014;20:1833-40.

14. Ansari MA, Fatima Z, Hameed S. Antifungal action of methylene blue involves mitochondrial dysfunction and disruption of redox and membrane homeostasis in C. albicans. Open Microbiol J 2016;10:12-22.

15. Delport A, Harvey BH, Petzer A, Petzer JP. Methylene blue and its analogues as antidepressant compounds. Metab Brain Dis 2017;32:1357-82.

16. Oz M, Lorke DE, Hasan M, Petroianu GA. Cellular and molecular actions of Methylene Blue in the nervous system. Med Res Rev 2011;31:93-117.

17. Morak-Mlodawska B, Jelen M. New biological properties of neuroleptic phenothiazines. Pol Merkur Lekarski 2007;23:459-61.

18. Wagner SJ, Skripchenko A, Robinette D, Foley JW, Cincotta L. Factors affecting virus photoinactivation by a series of phenothiazine dyes. Photochem Photobiol 1998;67:343-9.

19. Ramsay RR, Dunford C, Gillman PK. Methylene blue and serotonin toxicity: inhibition of monoamine oxidase A (MAO A) confirms a theoretical prediction. Br J Pharmacol 2007;152:946-51.

20. Couto N, Malys N, Gaskell SJ, Barber J. Partition and turnover of glutathione reductase from Saccharomyces cerevisiae: a proteomic approach. J Proteome Res 2013;12:2885-94.

21. Ziegler DM. Role of reversible oxidation-reduction of enzyme thiols-disulfides in metabolic regulation. Annu Rev Biochem 1985;54:305-29.

22. Buchholz K, Schirmer RH, Eubel JK, Akoachere $\mathrm{MB}$, Dandekar $\mathrm{T}$, Becker $\mathrm{K}$, et al. Interactions of methylene blue with human disulfide reductases and their orthologues from Plasmodium falciparum. Antimicrob Agents Chemother 2008;52:183-91.

23. Kristiansen JE. Dyes, antipsychotic drugs, and antimicrobial activity. Fragments of a development, with special reference to the influence of Paul Ehrlich. Dan Med Bull 1989;36:178-85.

24. Schirmer RH, Adler H, Pickhardt M, Mandelkow E. Lest we forget you--methylene blue.... Neurobiol Aging 2011;32:2325.

25. Howland RH. Methylene Blue: The long and winding road from stain to brain: Part 1 . J Psychosoc Nurs Ment Health Serv 2016;54:21-4

26. Tucker D, Lu Y, Zhang Q. From mitochondrial function to neuroprotection-an emerging role for methylene blue. Mol Neurobiol 2018;55:5137-53.

27. Miller LH, Good MF, Milon G. Malaria pathogenesis. Science 1994;264:1878-83.

28. Currier J, Sattabongkot J, Good MF. 'Natural' T cells responsive to malaria: evidence implicating immunological cross-reactivity in the maintenance of TCR alpha beta+ malaria-specific responses from non-exposed donors. Int Immunol 1992;4:985-94.
29. Schirmer RH, Coulibaly B, Stich A, Scheiwein M, Merkle H, Eubel J, et al. Methylene blue as an antimalarial agent. Redox Rep 2003;8:272-5.

30. Pompella A, Visvikis A, Paolicchi A, De Tata V, Casini AF. The changing faces of glutathione, a cellular protagonist. Biochem Pharmacol 2003;66:1499-503.

31. Lu SC. Glutathione synthesis. Biochim Biophys Acta 2013;1830:3143-53.

32. Pastore A, Piemonte F, Locatelli M, Lo Russo A, Gaeta LM, Tozzi G, et al. Determination of blood total, reduced, and oxidized glutathione in pediatric subjects. Clin Chem 2001;47:1467-9.

33. Kanzok SM, Fechner A, Bauer H, Ulschmid JK, Müller HM, Botella-Munoz J, et al. Substitution of the thioredoxin system for glutathione reductase in Drosophila melanogaster. Science 2001;291:643-6.

34. Toribio F, Martínez-Lara E, Pascual P, López-Barea J. Methods for purification of glutathione peroxidase and related enzymes. J Chromatogr B Biomed Appl 1996;684:77-97.

35. Müller T, Johann L, Jannack B, Brückner M, Lanfranchi DA, Bauer $\mathrm{H}$, et al. Glutathione reductasecatalyzed cascade of redox reactions to bioactivate potent antimalarial 1,4-naphthoquinones--a new strategy to combat malarial parasites. J Am Chem Soc 2011;133:11557-71.

36. Deponte M, Urig S, Arscott LD, Fritz-Wolf K, Réau $\mathrm{R}$, Herold-Mende $\mathrm{C}$, et al. Mechanistic studies on a novel, highly potent gold-phosphole inhibitor of human glutathione reductase. $\mathrm{J}$ Biol Chem 2005;280:20628-37.

37. Deponte M. Glutathione catalysis and the reaction mechanisms of glutathione-dependent enzymes. Biochim Biophys Acta 2013;1830:3217-66.

38. Thurston JP. The chemotherapy of Plasmodium berghei. I. Resistance to drugs. Parasitology 1953;43:246-52.

39. Pascual A, Henry M, Briolant S, Charras S, Baret $\mathrm{E}$, Amalvict $\mathrm{R}$, et al. In vitro activity of Proveblue (methylene blue) on Plasmodium falciparum strains resistant to standard antimalarial drugs. Antimicrob Agents Chemother 2011;55:2472-4.

40. Wirjanata G, Sebayang BF, Chalfein F, Prayoga, Handayuni I, Trianty L, et al. Potent ex vivo activity of naphthoquine and methylene blue against drugresistant clinical isolates of plasmodium falciparum and plasmodium vivax. Antimicrob Agents Chemother 2015;59:6117-24.

41. Adjalley SH, Johnston GL, Li T, Eastman RT, Ekland $\mathrm{EH}$, Eappen AG, et al. Quantitative assessment of Plasmodium falciparum sexual development reveals potent transmission-blocking activity by methylene blue. Proc Natl Acad Sci U S A 2011;108:E1214-23.

42. Müller O, Sié A, Meissner P, Schirmer RH, Kouyaté B. Artemisinin resistance on the Thai-Cambodian border. Lancet 2009;374:1419.

43. Mergenthaler P, Lindauer U, Dienel GA, Meisel A. Sugar for the brain: the role of glucose in physiological 
and pathological brain function. Trends Neurosci 2013;36:587-97.

44. Howarth C, Gleeson P, Attwell D. Updated energy budgets for neural computation in the neocortex and cerebellum. J Cereb Blood Flow Metab 2012;32:1222-32.

45. Du F, Zhu XH, Zhang Y, Friedman M, Zhang N, Ugurbil K, et al. Tightly coupled brain activity and cerebral ATP metabolic rate. Proc Natl Acad Sci U S A 2008;105:6409-14.

46. Akbar M, Essa MM, Daradkeh G, Abdelmegeed MA, Choi Y, Mahmood L, et al. Mitochondrial dysfunction and cell death in neurodegenerative diseases through nitroxidative stress. Brain Res 2016;1637:34-55.

47. Chaturvedi RK, Flint Beal M. Mitochondrial diseases of the brain. Free Radic Biol Med 2013;63:1-29.

48. Schapira AH. Mitochondrial diseases. Lancet 2012;379:1825-34.

49. Zeviani M, Taroni F, Gellera C, DiDonato S. Molecular pathogenesis of mitochondrial diseases. Progress in Cell Research 1995;5:223-4.

50. Swerdlow RH. Brain aging, Alzheimer's disease, and mitochondria. Biochim Biophys Acta 2011;1812:1630-9.

51. Hauptmann S, Keil U, Scherping I, Bonert A, Eckert A, Müller WE. Mitochondrial dysfunction in sporadic and genetic Alzheimer's disease. Exp Gerontol 2006;41:668-73.

52. Lin MT, Beal MF. Mitochondrial dysfunction and oxidative stress in neurodegenerative diseases. Nature 2006;443:787-95.

53. Müller WE, Eckert A, Kurz C, Eckert GP, Leuner K. Mitochondrial dysfunction: common final pathway in brain aging and Alzheimer's disease--therapeutic aspects. Mol Neurobiol 2010;41:159-71.

54. Wallace DC. A mitochondrial paradigm of metabolic and degenerative diseases, aging, and cancer: a dawn for evolutionary medicine. Annu Rev Genet 2005;39:359-407.

55. Wen Y, Li W, Poteet EC, Xie L, Tan C, Yan LJ, et al. Alternative mitochondrial electron transfer as a novel strategy for neuroprotection. $\mathrm{J}$ Biol Chem 2011;286:16504-15.

56. Gilman S. Alzheimer's disease. Perspect Biol Med 1997;40:230-45.

57. Lleó A, Greenberg SM, Growdon JH. Current pharmacotherapy for Alzheimer's disease. Annu Rev Med 2006;57:513-33.

58. Zhao M, Liang F, Xu H, Yan W, Zhang J. Methylene blue exerts a neuroprotective effect against traumatic brain injury by promoting autophagy and inhibiting microglial activation. Mol Med Rep 2016;13:13-20.

59. Octave JN, Pierrot N. Alzheimer's disease: cellular and molecular aspects. Bull Acad Natl Med 2008;192:323-31.

60. Hooper NM. Roles of proteolysis and lipid rafts in the processing of the amyloid precursor protein and prion protein. Biochem Soc Trans 2005;33:335-8.
61. Kolev MV, Ruseva MM, Harris CL, Morgan BP, Donev RM. Implication of complement system and its regulators in Alzheimer's disease. Curr Neuropharmacol 2009;7:1-8.

62. Silvestrelli G, Lanari A, Parnetti L, Tomassoni D, Amenta F. Treatment of Alzheimer's disease: from pharmacology to a better understanding of disease pathophysiology. Mech Ageing Dev 2006;127:148-57.

63. Maccioni RB, Muñoz JP, Barbeito L. The molecular bases of Alzheimer's disease and other neurodegenerative disorders. Arch Med Res 2001;32:367-81.

64. Necula M, Breydo L, Milton S, Kayed R, van der Veer $\mathrm{WE}$, Tone $\mathrm{P}$, et al. Methylene blue inhibits amyloid Abeta oligomerization by promoting fibrillization. Biochemistry 2007;46:8850-60.

65. Medina DX, Caccamo A, Oddo S. Methylene blue reduces a $\beta$ levels and rescues early cognitive deficit by increasing proteasome activity. Brain Pathol 2011;21:140-9.

66. Paban V, Manrique C, Filali M, Maunoir-Regimbal $\mathrm{S}$, Fauvelle F, Alescio-Lautier B. Therapeutic and preventive effects of methylene blue on Alzheimer's disease pathology in a transgenic mouse model. Neuropharmacology 2014;76:68-79.

67. Mori T, Koyama N, Segawa T, Maeda M, Maruyama $\mathrm{N}$, Kinoshita $\mathrm{N}$, et al. Methylene blue modulates $\beta$-secretase, reverses cerebral amyloidosis, and improves cognition in transgenic mice. $\mathrm{J}$ Biol Chem 2014;289:30303-17.

68. Atamna H, Kumar R. Protective role of methylene blue in Alzheimer's disease via mitochondria and cytochrome c oxidase. J Alzheimers Dis 2010;20 Suppl 2:S439-52.

69. Wagner G. Towards a life prolonging pill? Small molecules with anti-ageing properties. Curr Drug Targets 2006;7:1531-7.

70. Peter C, Hongwan D, Küpfer A, Lauterburg $\mathrm{BH}$. Pharmacokinetics and organ distribution of intravenous and oral methylene blue. Eur $\mathrm{J}$ Clin Pharmacol 2000;56:247-50.

71. Rojas JC, Simola N, Kermath BA, Kane JR, Schallert T, Gonzalez-Lima F. Striatal neuroprotection with methylene blue. Neuroscience 2009;163:877-89.

72. van Bebber F, Paquet D, Hruscha A, Schmid B, Haass C. Methylene blue fails to inhibit Tau and polyglutamine protein dependent toxicity in zebrafish. Neurobiol Dis 2010;39:265-71.

73. Calderone RA, Fonzi WA. Virulence factors of Candida albicans. Trends Microbiol 2001;9:327-35.

74. Perlroth J, Choi B, Spellberg B. Nosocomial fungal infections: epidemiology, diagnosis, and treatment. Med Mycol 2007;45:321-46.

75. Bassetti M, Merelli M, Righi E, Diaz-Martin A, Rosello EM, Luzzati R, et al. Epidemiology, species distribution, antifungal susceptibility, and outcome of candidemia across five sites in Italy and Spain. J Clin Microbiol 2013;51:4167-72. 
76. Diekema D, Arbefeville S, Boyken L, Kroeger J, Pfaller M. The changing epidemiology of healthcareassociated candidemia over three decades. Diagn Microbiol Infect Dis 2012;73:45-8.

77. Lewis K. Persister cells: molecular mechanisms related to antibiotic tolerance. Handb Exp Pharmacol 2012;(211):121-33.

78. Maubon D, Garnaud C, Calandra T, Sanglard D, Cornet M. Resistance of Candida spp. to antifungal drugs in the ICU: where are we now? Intensive Care Med 2014;40:1241-55.

79. Pfaller MA, Messer SA, Boyken L, Tendolkar S, Hollis RJ, Diekema DJ. Geographic variation in the susceptibilities of invasive isolates of Candida glabrata to seven systemically active antifungal agents: a global assessment from the ARTEMIS Antifungal Surveillance Program conducted in 2001 and 2002. J Clin Microbiol 2004;42:3142-6.

80. Yapar N. Epidemiology and risk factors for invasive candidiasis. Ther Clin Risk Manag 2014;10:95-105.

81. Lamps LW, Lai KK, Milner DA Jr. Fungal infections of the gastrointestinal tract in the immunocompromised host: an update. Adv Anat Pathol 2014;21:217-27.

82. Staniszewska M, Bondaryk M, Pilat J, Siennicka $\mathrm{K}$, Magda U, Kurzatkowski W. Virulence factors of Candida albicans. Przegl Epidemiol 2012;66:629-33.

83. De Backer MD, Magee PT, Pla J. Recent developments in molecular genetics of Candida albicans. Annu Rev Microbiol 2000;54:463-98.

84. Calderone R, Odds FC, Boekhout T. Candida albicans: fundamental research on an opportunistic human pathogen. FEMS Yeast Res 2009;9:971-2.

85. Fox EP, Nobile CJ. A sticky situation: untangling the transcriptional network controlling biofilm development in Candida albicans. Transcription 2012;3:315-22.

86. Ganguly S, Mitchell AP. Mucosal biofilms of Candida albicans. Curr Opin Microbiol 2011;14:380-5.

87. Douglas LJ. Candida biofilms and their role in infection. Trends Microbiol 2003;11:30-6.

88. Inglis DO, Sherlock G. Ras signaling gets fine-tuned: regulation of multiple pathogenic traits of Candida albicans. Eukaryot Cell 2013;12:1316-25.

89. Sudbery PE. Growth of Candida albicans hyphae. Nat Rev Microbiol 2011;9:737-48.
90. Hube B. Fungal adaptation to the host environment. Curr Opin Microbiol 2009;12:347-9.

91. Pierce JV, Dignard D, Whiteway M, Kumamoto CA. Normal adaptation of Candida albicans to the murine gastrointestinal tract requires Efglp-dependent regulation of metabolic and host defense genes. Eukaryot Cell 2013;12:37-49.

92. Szodoray L. Diszdoktor avatás a debreceni Orvostudományi Egyetemen. Conferring of the Doctor Honoris Causa title at the University School of Medicine of Debrecen. (Frigyes Verzár). Orv Hetil 1967;108:799-800.

93. Chandra J, Kuhn DM, Mukherjee PK, Hoyer LL, McCormick T, Ghannoum MA. Biofilm formation by the fungal pathogen Candida albicans: development, architecture, and drug resistance. J Bacteriol 2001;183:5385-94.

94. Kojic EM, Darouiche RO. Candida infections of medical devices. Clin Microbiol Rev 2004;17:255-67.

95. Fox EP, Singh-Babak SD, Hartooni N, Nobile CJ. Biofilms and Antifungal Resistance. In: Coste AT, Vandeputte P, editors. Antifungals: From Genomics to Resistance and the Development of Novel Agents. Wymondham: Caister Academic Press; 2015. p. 71-90.

96. Andes DR, Safdar N, Baddley JW, Playford G, Reboli AC, Rex JH, et al. Impact of treatment strategy on outcomes in patients with candidemia and other forms of invasive candidiasis: a patient-level quantitative review of randomized trials. Clin Infect Dis 2012;54:1110-22.

97. Khanal A, Bui MP, Seo SS. Microgel-encapsulated methylene blue for the treatment of breast cancer cells by photodynamic therapy. J Breast Cancer 2014;17:18-24.

98. Teichert MC, Jones JW, Usacheva MN, Biel MA. Treatment of oral candidiasis with methylene bluemediated photodynamic therapy in an immunodeficient murine model. Oral Surg Oral Med Oral Pathol Oral Radiol Endod 2002;93:155-60.

99. Machado-de-Sena RM, Corrêa L, Kato IT, Prates RA, Senna AM, Santos CC, et al. Photodynamic therapy has antifungal effect and reduces inflammatory signals in Candida albicans-induced murine vaginitis. Photodiagnosis Photodyn Ther 2014;11:275-82. 